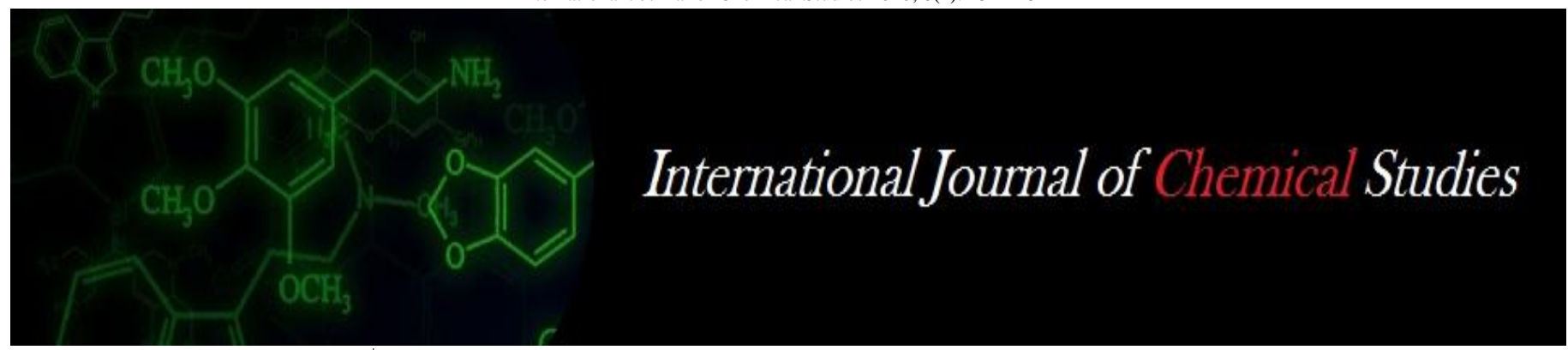

P-ISSN: 2349-8528

E-ISSN: 2321-4902

IJCS 2020; 8(1): 2321-2324

(C) 2020 IJCS

Received: 15-11-2019

Accepted: 18-12-2019

\section{Avtar Singh}

Department of Forestry \&

Natural Resources, Punjab

Agricultural University,

Ludhiana, Punjab, India

\section{GPS Dhillon}

Department of Forestry \& Natural Resources, Punjab Agricultural University, Ludhiana, Punjab, India

\section{Parmeet Singh Dhillon} Department of Forestry \& Natural Resources, Punjab Agricultural University, Ludhiana, Punjab, India
Corresponding Author: Avtar Singh

Department of Forestry \& Natural Resources, Punjab Agricultural University, Ludhiana, Punjab, India

\section{Survival and growth performance of Eucalyptus clones irrigated with effluents from liquor factory}

\author{
Avtar Singh, GPS Dhillon and Parmeet Singh Dhillon
}

DOI: https://doi.org/10.22271/chemi.2020.v8.i1ai.8614

\begin{abstract}
Eucalyptus is one of the most widely planted genus because of its fast growth rate, multiple uses, ability to tolerate and grow well on degraded and unfertile soils. The study was based on nine Eucalyptus clones (C-411, C-2045, C-413, PE-5, PE-11, PE-1, PE-7, PE-8 and PE-6) planted in semi-arid conditions irrigated with effluents from liquor factory. All the clones adapted well with very high survival rate. Differences among the clones were found to be significant for tree height and diameter at age of 4.5, 8 and 13 months. Clone C-413 and PE-5 were found to be promising with respect to wood volume. performed better than other clones. The height growth was relatively fast with tree height growth upto $7.23 \mathrm{~m}$ after 13 months. The result concluded that liquor factory effluents may be recommended as a good source of irrigation to Eucalyptus trees.
\end{abstract}

Keywords: survival, diameter, tree height, effluents, phyto-remediation

\section{Introduction}

Eucalyptus is a versatile genus and is widely planted across the globe because of fat growth, short rotation age and adaptability to a varied range of edaphic and climatic conditions (Goorand Barney 1968) ${ }^{[3]}$. Its Eucalyptus was introduced in India in the early $18^{\text {th }}$ century and in 1860 in Punjab (Sundar 1984) [11]. In India, the majority of Eucalyptus plantations on government, forest, farm lands, community lands and along road / rail / canal strips are of seed origin.

Eucalyptus hybrid and E. tereticornis are the two most widely planted Eucalyptus in India. Many species can tolerate flooding or swamp lands and are given vernacular names accordingly (Parsons et al. 1991, Ladiges and Kelso 1997) e.g. flooded gum (E. grandis), swamp gums (E. camphoraand E. ovate), river red gum (E. camaldulensis) and swamp mahogany (E.robusta). Species intolerance to waterlogging generally shows no morphological changes and no recovery of gas exchange during exposure to the waterlogged condition.

Eucalyptus is a versatile genus, belongs to Myrtaceae family which can adapt to a varied range of edaphic and climatic conditions (Goorand Barney 1968) ${ }^{[3]}$. It can grow in a wide variety of soil conditions but for its proper growthit needs fertile, well-drained sandy loamy to loamy soilshaving suitable moisture. Eucalyptusis very fast growing tree and attains a height of about $30 \mathrm{~m}$ and more with a straight clean bole in a short rotation of about 8-10 years. Among 700 species of Eucalyptus, majority are native of Australian continent. It was introduced in India in the early $18^{\text {th }}$ century. In Punjab, it was introduced in 1860 by the Director of canals on Madhopur Headworks. In India, the majority of Eucalyptus plantations on government, forest, farm lands, community lands and along road / rail / canal strips are of seed origin. Large scale eucalypt plantations in the country were planted for various reasons varying from state to state. These plantations were raised to rejuvenate the denuded and barren hilly areas and replace the degraded natural forests. Most of the eucalypt plantations in India were raised during the time span of $1960-1980$.

Eucalyptus hybrid and E. tereticornis are the two most widely planted Eucalyptus in India. Many species can tolerate flooding or swamp lands and are given vernacular names accordingly (Parsons et al. 1991, Ladiges and Kelso 1997) e.g. flooded gum (E. grandis), swamp gums (E. camphora and E. ovate), river red gum (E. camaldulensis) and swamp mahogany (E. robusta). Species intolerance to waterlogging generally shows no morphological changes and no recovery of gas exchange during exposure to the waterlogged 
condition.

The partially treated sewage waste, industrial waste and farm waste and it released into a natural body of water is generally known as effluent, and the such treated waste used for irrigation in plants is called as effluent irrigation. Waste water used for irrigating plantation is a popular substitute to river discharge and thus river water is protected by such efforts. The preference for irrigating tree plantations over agricultural crops has been credited to the high promising growth rates and the testified high rates of water use. Moreover, effluents in the food-processing industries, liquor industries, dairy farms and municipal sewerage treatment plants have great amounts of nutrients such as phosphorus, nitrogen and so on. Though, nutrient unavailability is the main cause for plants and crops not succeeding their potential growth capacity. According to Marecos et al. (1989) the effluents should be used as a nutrients rich water resource to irrigate plantation and it is a good approach to replace commercial fertilizers. On the other hand, continual effluent irrigation could change the properties of soil like change in nutrient concentration, $\mathrm{pH}$ and so on.

Tree breeding is the application of genetic principles and reproductive principles for enhancing wood productivity or tolerance to biotic/ abiotic stresses. Considerable genetic diversity exists in Eucalyptus as this genus is of high outcrossing nature and natural hybridization between species of the genus is often found. The high variation for tolerance to salt affected sites and marshy lands has been reported Grieve et al. $1999^{[4]}$. These variations can be captured through selection of tolerant genotypes to abiotic stresses and by using planting stock originated from the tolerant trees.

Material and Methods

Site and Climatic Conditions: The experiment was conducted at Liquor Factory Macchana, near Sangat Mandi, Punjab. It is situated at $30^{\circ} 3{ }^{\prime} 55.4^{\prime \prime} \mathrm{N}$ latitude and $74^{\circ} 51^{\prime} 18.6^{\prime \prime} \mathrm{E}$ longitude at an elevation of about 202 (m) above mean sea level. In general, the climate is sub-tropical with a long duration dry spell from October to mid-June. May and June are the warmest months with severe evapo-transpiration losses, whereas, December to February are the coldest months. The area receives an average rainfall of about 421 $\mathrm{mm}$ per annum and 3/4th of total amount of rainfall is predictable during July to September with an average of about 31 rainy days.

Plant Material and experimental details: Nine clones of Eucalyptus (C-411, C-2045, C-413, PE-5, PE-11, PE-1, PE-7, PE-8, and PE-6) were studied. The uniform size plants were used for the study.

Nine clones were used for the study. Six clones developed by PAU and three were commercial clones. The details of the clone are given Table1. The plants of eight clones were raised in the Mist Chamber of the Department of Forestry and Natural Resources and one clone (C-411) was procured from Prakriti clonal Agrotech, a leading supplier of clonal planting stock. The plants of each clone were shifted to perforated polybags filled with silt and farmyard manure (1:1) and maintained in the nursery. The uniform size plants were used for the study. The experiment was planted during March 2016. Each clone was replicated four times with Randomized Block Design and plot size of 5 plants. One row of the nonexperimental plants was planted around the trial. After planting, the irrigation was given. Regular irrigation, weeding and other plant protection measures was given as per the recommended practices. The irrigation was from the industrial effluent of the liquor factory.

Table 1: Details of the Eucalyptus clones used in the study

\begin{tabular}{|c|c|c|c|}
\hline S. No. & Name & Origin of plus tree & Progeny number \\
\hline 1 & C-411 & ITC, Bhadrachalam paper mills & - \\
\hline 2 & C-2045 & ITC, Bhadrachalam paper mills & - \\
\hline 3 & C-413 & ITC, Bhadrachalam paper mills & - \\
\hline 4 & PE-1* & PAU, Ludhiana & L-55 \\
\hline 5 & PE-7* & HAU, Hisar & HS-6 \\
\hline 6 & PE-5* & Orissa University of Agriculture and Technology, Bhubneshwar & OUAT,ET-10 \\
\hline 7 & PE-6* & TNAU, Coimbatore & FC\&RI, MTP/ET-5 \\
\hline 8 & PE-11* & Australia Seed Centre & $13547 /$ JD1043 \\
\hline 9 & PE-8 & Australia Seed Centre & $16547 / J D 1572$ \\
\hline
\end{tabular}

*These clones were developed by Punjab Agricultural University, Ludhiana

\section{Observations and statistical analysis:}

Data on survival (\%), plant height and diameter at breast height $(\mathrm{DBH})$ were recorded three times at the age of $4.5,8$ and 13 months after planting with the help of measuring Ravis altimeter and vernier's calliper, respectively. Volume index $\left(\mathrm{D}^{2} \mathrm{H}\right)$ was worked out after age 13 months, as it is good indicator of amount of wood production. Statistical analysis was performed as per the procedure laid down for Completely Randomized block design (CRBD). Analysis of variance, least significant difference (LSD) was calculated for the interpretation of results of the study following Panse and Sukhatme (1989) ${ }^{[5]}$.

\section{Results and Discussion \\ Survival}

The survival of clones varied from 95 to 100 per cent. Clones C-413, PE-11, PE-7 and PE-6 recorded 100 per cent survival, whereas C-411, C-2045, PE-5, PE-1 and PE-8 had 95 (\%) values. The differences among clones were non-significant. The pursued data showed that all the Eucalyptus clones established well at the site irrigated with effluent. Keeping in view the salinity conditions of the soil and irrigation water, the survival was exceptionally well. The role of the trees for remediation of such sites is well documented (Shah et al. 2010, Singh et al. 2010) ${ }^{[8,9]}$.

Piper et al. (2011) ${ }^{[6]}$ also reported good establishment of seedlings of Eucalyptus moluccana and E. tereticornis irrigated with industrial effluents. In another study, the tolerance of two tree species Eucalyptus grandis and E. urophylla irrigated with pulp mill effluent was satisfactory (Rezende et al. 2010) [7]. In the present study, the better survival may also be due to the light textured soil where the seepage was very fast. 


\section{Growth traits}

Data of height growth of Eucalyptus clones at the age of 4.5, 8and 13monthsare given in Table 2. Significant differences $(\mathrm{p}<0.05)$ were observed among the clones at all ages. Clone PE-1 was significantly superior to other clones except with PE-6, PE-11 and C-413. Clone PE-8 registered as the lowest value $(145.8 \mathrm{~cm})$. After 8 months, C-413 recorded the highest value $(5.12 \mathrm{~m})$ and was statistically superior to other clones. It was followed by six clones i.e. PE-11, PE-1, C-2045, PE-6, PE-5 and C-411. The bottom rank was again in case of PE-8. Clone C-413 maintained the top rank with value of $7.23(\mathrm{~m})$ and was significantly superior to all the clones. It was followed by clones PE-5, PE-6 and C-2045. Clone PE-8 registered the lowest value $(5.49 \mathrm{~m})$.

Differences among the clones for diameter were significant at all ages i.e. 4.5, 8 and 13 months after planting (Table 3). Clone PE-1 attained the maximum DBH $(29.8 \mathrm{~mm})$ at age of 4.5 months and was significantly superior to other clones. The lowest mean diameter value $(16.9 \mathrm{~mm})$ was registered by clone C-2045 which was at par with three other clones PE-8, C-411 and PE-7. The mean DBH of PE-1 (56.12 mm) at age of 8 months was found to be maximum and was at par with C$413(51.86 \mathrm{~mm})$ but was significantly superior to other clones. The lowest value was registered by clone PE-8 (39.36 mm). The rankings of clones from maximum to minimum via mean diameter was noticed as PE-1>C-413> PE-6> PE- 5> PE$11>\mathrm{C}-2045>\mathrm{PE}-7>\mathrm{C}-411>\mathrm{PE}-8$.At age of 13 months, clone PE-5 attained the top rank $(79.91 \mathrm{~mm})$ which was, however, at par with C-413 (78.77 mm), PE-6 (78.57 mm) and PE-1 (76.43 $\mathrm{mm})$ but was superior to other clones. The lowest mean diameter value was registered by clone PE-8 with an average value of $62.61(\mathrm{~mm})$. The rankings of clones was PE5> C-413> PE-6> PE- 1> C-411> PE-7> C-2045> PE$11>\mathrm{PE}-8$. On the basis of overall performance of mean height and diameter after 13 months it is concluded that clone C-413 and PE-5 are the most promising clones for height and diameter respectively. The volume index $\left(D^{2} \mathrm{H}\right)$ also differed significantly among the clones. C-413 was found to be statistically superior to all other clones, except PE-5 (Fig1). The relative rankings were in order of C-513>PE-5>PE6>PE-1>C-411>C-2045>PE-11>PE-7>PE-8.

The results of the present study showed the significant differences $(p<0.05)$ among the clones were found for both all the growth traits at all the three ages (Table 2, Table 3 and Fig 1). The differential response of clones to any environment/abiotic stress may be due to their different genetic make-up. Grieve et al. (1999) ${ }^{[4]}$ found the variation among clones of E. camaldulensis and E. rudis which were irrigated with saline water. Eucalyptus trees are effective for their ability to combat waterlogging, heavy water remediation and also provide biomass yields from such sites (Bilal et al. 2014) ${ }^{[1]}$. Clone PE-1 performed better age of 4.5 months, but clone $\mathrm{C}-413$ attained the top rank in height at age of 8 months and 13 months. The relative ranking of clones changed with time, which is often observed in the genetic trials of trees (Dhillon et al. 2010) ${ }^{[2]}$. Effluents are known to have positive effect on the growth of Eucalyptus. Singh and Bhati (2003) [10] concluded that municipal effluent did not show any toxicity to the seedlings of E. camaldulensis up to 24 months age.

Table 2: Height (m) of Eucalyptus clones irrigated with effluents at various ages

\begin{tabular}{|c|c|c|c|}
\hline \multirow{2}{*}{ Clone } & \multicolumn{3}{|c|}{ Age (months) } \\
\cline { 2 - 4 } & $\mathbf{4 . 5}$ & $\mathbf{8}$ & $\mathbf{1 3}$ \\
\hline C-411 & 1.59 & 3.85 & 6.06 \\
\hline C-2045 & 1.57 & 4.22 & 6.47 \\
\hline C-413 & 1.85 & 5.12 & 7.23 \\
\hline PE-5 & 1.53 & 3.97 & 6.60 \\
\hline PE-11 & 1.87 & 4.24 & 6.13 \\
\hline PE-1 & 2.04 & 4.22 & 6.11 \\
\hline PE-7 & 1.55 & 3.71 & 5.67 \\
\hline PE-8 & 1.46 & 3.54 & 5.49 \\
\hline PE-6 & 1.87 & 4.22 & 6.50 \\
\hline Mean \pm SE & $1.70 \pm 0.068$ & $4.13 \pm 0.33$ & $6.25 \pm 0.39$ \\
\hline LSD $($ P $<0.05)$ & 0.25 & 0.48 & 0.52 \\
\hline
\end{tabular}

Table 3: Diameter at breast height (DBH, mm) of Eucalyptus clones irrigated with effluents

\begin{tabular}{|c|c|c|c|}
\hline \multirow{2}{*}{ Clone } & \multicolumn{3}{|c|}{ Age (months) } \\
\cline { 2 - 4 } & $\mathbf{4 . 5}$ & $\mathbf{8}$ & $\mathbf{1 3}$ \\
\hline C-411 & 18.9 & 41.80 & 69.02 \\
\hline C-2045 & 16.9 & 42.18 & 65.60 \\
\hline C-413 & 21.1 & 51.86 & 78.77 \\
\hline PE-5 & 21.0 & 47.46 & 79.91 \\
\hline PE-11 & 22.3 & 45.12 & 65.17 \\
\hline PE-1 & 29.8 & 56.12 & 76.43 \\
\hline PE-7 & 20.3 & 42.10 & 66.22 \\
\hline PE-8 & 17.5 & 39.36 & 62.61 \\
\hline PE-6 & 24.7 & 50.29 & 78.57 \\
\hline Mean \pm SE & $21.04 \pm 1.31$ & $46.25 \pm 1.78$ & $71.37 \pm 1.53$ \\
\hline LSD (P<0.05) & 3.49 & 5.56 & 6.68 \\
\hline
\end{tabular}




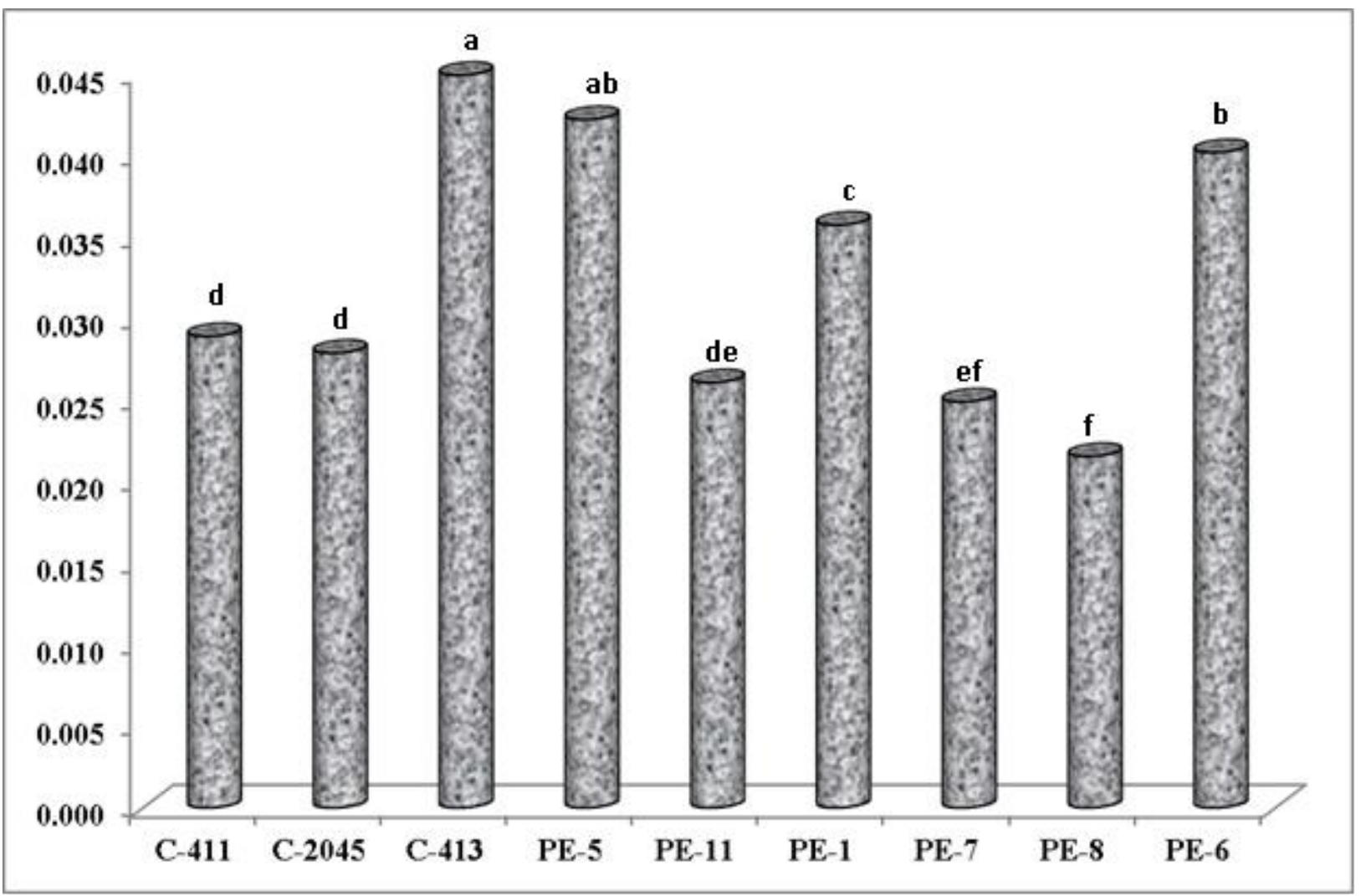

Fig 1: Volume Index (D2H, m3) of Eucalyptus clones irrigated with liquor factory effluents

\section{Conclusions}

The field study involving nine Eucalyptus clones planted in semi-arid conditions with irrigation source found wide variation for all the growth traits with significant differences among clones. Clone C-413 and PE-5 performed better than other clones. More reliable and precise information will come out one the trees reach rotation age. Initial results show that, effluents from liquor factory may be recommended as a good source of irrigation to Eucalyptus trees and will enhance the productivity.

\section{References}

1. Bilal H, Ali SS, Kim KM. Potential of Eucalyptus in the remediation of environmental problems:-a review, Inter J Innovation and Scientific Res. 2014; 4:136-144.

2. Dhillon GPS, Singh A, Brar HS. Age-age correlations for early selections in Eucalyptus tereticornis. Environment and Ecology. 2010; 28:156-159.

3. Goor AY, Barney CW. Forest Tree Planting in Arid Zones. Ronald Press, New York, 1968.

4. Grieve CM, Guzy MR, Poss JA, Shannon MC. Screening Eucalyptus clones for salt tolerance. Hort Sci. 1999; 34:867-870.

5. Panse VG, Sukhatme PV. Statistical methods for agricultural workers. Pp 359. Indian council of agricultural research, New Delhi, 1989.

6. Piper AD, David L, Menzies NW. Irrigation with industrial effluent leads to mortality of coppice growth in Eucalyptus. Australian Forestry. 2011; 74:170-179.

7. Rezende AAP, De Matos AT, Silva CM, Neves JCL. Irrigation of eucalyptus plantation using treated bleached kraft pulp mill effluent. Water Sci Technol. 2010; 62:2150-2156.

8. Shah FUR, Ahmad N, Masood KR, Peralta-videa JR, Zahid DM, Zubair M. Response of Eucalyptus camaldulensis to irrigation with the Hudiara drain effluent. International J Phytorem. 2010; 12:343-357.

9. Singh A, Toky OP, Dhillon GPS. Growth performances of Eucalyptus tereticornis and E. camaldulensis progenies under various levels of soil salinity. Indian For. 2010; 136(2):1610-1615.

10. Singh G, Bhati M. Growth, biomass production, and nutrient composition of Eucalyptus seedlings irrigated with municipal effluent in loamy sand soil of Indian Desert. Journal Plant Nutrition. 2003; 26:2469-2488.

11. Sundar S. Some aspects of Eucalyptus hybrid. In: Workshop on Eucalyptus Plantations. Bangalore, Indian Statistical Institute, 1984. 